\title{
A PRODUÇÃO DA ESCRITA - UMA EXPERIÊNCIA CURRICULAR - NO COTIDIANO DA SALA DE AULA: CONTRIBUIÇÕES DA EDUCAÇÃO E DA LINGUÍSTICA
}

\section{THE PRODUCTION OF WRITING - A CURRICULAR EXPERIENCE - IN THE DAILY LIFE OF THE CLASSROOM: CONTRIBUTIONS OF EDUCATION AND LINGUISTICS}

\author{
SILVA, Patrícia Tavares da ${ }^{1}$ \\ GRANJA, Tania de Assis Souza ${ }^{2}$ \\ ABREU, Kátia Nazareth Moura de ${ }^{3}$
}

\begin{abstract}
RESUMO
Neste texto, o foco é refletir sobre a produção da escrita dos alunos de uma classe de aceleração, em uma escola pública de Ensino Fundamental do município de São Gonçalo, a partir de uma pesquisa de abordagem etnográfica realizada. Partindo do currículo "oficial" proposto pela política educacional local, abordam-se, também, os processos de recontextualização em que este currículo "prescrito" se insere, decorrente das práticas pedagógicas realizadas no cotidiano da sala de aula. Este estudo contribui, de um lado, para pensar o currículo e as práticas pedagógicas que orbitam em torno dele, nas suas tentativas de responder às diretrizes "oficiais" estabelecidas para as classes de aceleração e, de outro, refletir sobre a consolidação de competências comunicativas e textuais que podem surgir na produção escrita desses alunos, a partir de processos e subprocessos que estão implicados nessa tarefa.
\end{abstract}

PaLAVRAS-CHAVE: Produção da escrita; práticas pedagógicas; currículo; educação; linguística.

\begin{abstract}
In this text, the focus is to reflect on the production of the writing of students of an acceleration class, in a public elementary school in the municipality of São Gonçalo, from an ethnographic research conducted. Starting from the "official" curriculum proposed by the local educational policy, we also approach the processes of recontextualization in which this "prescribed" curriculum is inserted, resulting from pedagogical practices carried out in the daily life of the classroom. This study contributes, on the one hand, to a reflection about the curriculum and pedagogical practices that orbit around it, in their attempts to respond to the "official"
\end{abstract}

\footnotetext{
${ }^{1}$ Universidade do Estado do Rio de Janeiro (UERJ) / Faculdade de Formação de Professores (FFP). São Gonçalo, RJ, Brasil. ORCID: https://orcid.org/0000-0003-3657-0139 e-mail: ptavaressilva@outlook.com 2 Universidade do Estado do Rio de Janeiro (UERJ) / Faculdade de Formação de Professores (FFP). São Gonçalo, RJ, Brasil. ORCID: https://orcid.org/0000-0003-3657-0139 e-mail: tasgranja@gmail.com

${ }^{3}$ Universidade do Estado do Rio de Janeiro (UERJ) / Faculdade de Formação de Professores (FFP). São Gonçalo, RJ, Brasil. ORCID: https://orcid.org/0000-0002-8505-4512 e-mail: kabreu00@gmail.com
} 
DOI: $10.12957 / \mathrm{e}-\mathrm{mosaicos} .2020 .51201$

guidelines established for the acceleration classes and, on the other, to reflect on the consolidation of communicative and textual competencies that may arise in the written production of these students, from processes and subprocesses that are implicated in this task.

KEYWORDS: Writing production; pedagogical practices; curriculum; education; linguistic.

\section{INTRODUÇÃo}

A escola pública acolhe, ao longo do processo de escolarização, diferentes tipos de alunos, com diferentes origens sociais, diferentes capacidades e uma enorme diversidade e, por que não dizer, acolhe as diferenças cuja complexidade se reflete no processo educativo, nos conteúdos a serem ensinados e nas práticas pedagógicas que estão à volta do currículo escolar. É nessa diversidade que se coloca um imenso desafio para o trabalho docente, tendo em vista que é fundamental compreender a prática educativa institucionalizada que, a bem da verdade, é um "modelo" educativo determinado que traz em si as finalidades sociais, culturais, cognitivas, intelectuais e, por que não, políticas da instituição escolar como um todo, tendo no currículo a via preferencial para que os alunos tenham acesso ao conhecimento e à cultura.

Assim sendo, inicialmente, trazemos alguns elementos da observação sistemática da dinâmica cotidiana da sala de aula e de seu currículo, onde orbitam as práticas pedagógicas. A experiência curricular, vivida numa classe de aceleração, constituiu-se de atividades pedagógicas oriundas do trabalho colaborativo com os professores, cujo foco na produção da escrita desses alunos permitiu o acompanhamento desta turma durante um ano letivo. Enfatizamos, também, os processos de recontextualização da política curricular, dessa proposta local, que estão muito presentes nas práticas pedagógicas realizadas pelos sujeitos educativos que ocupam o espaço escolar e que repercutem, sobremaneira, na dinâmica da sala de aula. Num segundo momento, abordamos a produção da escrita, como definida por Koch; Elias (2014), oportunizando um olhar agudo, mais fino de como o processo cognitivo de tal produção é realizado, tal qual definem Hayes \& Flower (1980).

\section{NOTAS SOBRE O CURRÍCULO, A PRÁTICA PEDAGÓGICA E O COTIDIANO DA SALA DE AULA}

Pensando no currículo escolar, vale lembrar o que nos ensina Sacristán (2000, p. 15), afirmando que, "quando definimos o currículo estamos descrevendo a concretização das funções da própria escola e a forma particular de enfocá-las [...] para um nível ou modalidade de educação, numa trama institucional". Dependendo das condições em que se realiza este currículo, torna-se algo dinâmico e transbordante de significados.

Apoiando-nos em Goodson (1997) e Sacristán (2000), lançamos mão do conceito de currículo como uma construção social na medida em que as experiências curriculares ganham significados atribuídos pelos sujeitos educativos que delas participam. Entendendo, também, que o currículo é recontextualizado pelos 
professores e, assim, modelado de forma particular pelas práticas pedagógicas, pelas propostas e práticas curriculares que são realizadas no "chão da escola", estas que são, também, marcadas pelo hibridismo, como analisadas por Ball (2000) e Lopes $(2005,2008)$. Assim, afirmamos que as políticas que chegam às escolas são apropriadas de modo muito singular, por cada instituição de ensino, como é o caso da política local, no que tange às classes de aceleração da rede.

Nesse sentido, podemos inferir que as experiências curriculares são construídas por quem delas participa e são (re)configuradas nos contextos em que são vividas. Assim sendo, a experiência que vivenciamos durante $o$ ano de 2019, com a pesquisa de campo, em uma classe de aceleração, revela-nos que muitos tipos de ações intervêm na configuração que o currículo adquire num "mundo" de interações culturais e sociais que não é independente ou indiferente aos sujeitos que dele participam: professores, alunos e, neste caso, também nós, os pesquisadores. Nesse sentido, significa dizer que o currículo é resultante de diversas operações e contextos concretos, do manejo dos professores, do material didático utilizado e, sobretudo, das aprendizagens que os alunos realizam, dentre outros aspectos, que dão forma, transformam, dão "vida" e significado ao currículo escolar.

O currículo estabelecido pela equipe gestora da educação municipal relativo ao programa de aceleração de estudos, compactando o $8^{\circ}$ e $9^{\circ}$ anos de escolaridade, em um ano letivo, cumpre uma função por meio dos conteúdos que são ministrados e das formas assumidas por estes, sobretudo, na impregnação das práticas que se realizam. Assim, como aponta Sacristán (2000, p. 26) "[...] o currículo é o cruzamento de práticas diferentes e se converte em configurador, por sua vez, de tudo o que podemos denominar como prática pedagógica [...]", que se realizam nas salas de aula, no entrelaçamento dos conteúdos ensinados no cotidiano da escola. É a partir dessa perspectiva que podemos afirmar que o currículo adquire forma e significado educativo à medida que passa por processos, transformações, adaptações, ressignificações, interpretações, hibridizações e ajustes decorrentes das atividades práticas diárias que são desenvolvidas no cotidiano da escola, tornando-se, assim, o currículo um elemento que dá materialidade a uma realidade curricular e à prática pedagógica, entendidos como um conjunto e indissociáveis (SACRISTÁN, 2000).

Assim, na pesquisa de abordagem etnográfica que realizamos, nos propusemos a analisar o movimento e a dinâmica da sala de aula e, sobretudo, conhecer a produção da escrita dos alunos de uma classe de aceleração. Afora isso, enfatizamos a imersão de nós, pesquisadores, numa rede de sentidos e significados compartilhados pelo grupo social pesquisado, o que possibilitou a ocorrência do que Corsaro (2005, p. 446) nomeia de "tornar-se nativo" na pesquisa etnográfica, ou, dito em outras palavras, a nossa aceitação pelos alunos e o acolhimento dos professores permitiu que adquiríssemos o status de membro daquele grupo, convivendo com eles, participando daquele universo e daquela cultura escolar, entendida como um conjunto de crenças, atitudes, expectativas e comportamentos construídos e compartilhados por este grupo social (TURA, 2002). 
DOI: $10.12957 / \mathrm{e}-\mathrm{mosaicos} .2020 .51201$

Entendemos que o currículo é uma construção social, ideia que é compartilhada por Goodson (1997), Sacristán (2000), Silva (2002) e Tura (2002), e sua existência e materialidade ocorrem a partir da experiência humana. Com este olhar, podemos inferir que há uma relação muito estreita entre o currículo, a prática pedagógica e a interação que é estabelecida entre os sujeitos educativos. Essa interação provinda da relação professor-aluno se desdobra no que Tardif (2008, p. 231) denomina de '[...] tramas interacionais que comandam a 'lógica' das ações em sala de aula", o que, em outras palavras, significa dizer que cada sala de aula tem um certo modo de funcionamento ou, melhor, um modus operandi e características peculiares, o que demanda intervenções, também, diferenciadas por parte dos professores dando "tonalidades" distintas para as práticas pedagógicas na construção do currículo.

Nesse sentido, cabe destacar que na observação da prática pedagógica na escola Azul (nome fictício), consideramos as diversas oportunidades de aprendizagem que foram apresentadas aos alunos desta classe de aceleração, a GIII (Grupo III), por meio de atividades pedagógicas resultantes do trabalho colaborativo com alguns professores, em especial, com a professora de Língua Portuguesa.

Destacamos, aqui, que esse trabalho colaborativo surgiu, naturalmente, no curso do trabalho de campo. Inicialmente, ocorreu com maior ênfase com a professora de Língua Portuguesa, a partir dos textos e temas trazidos por ela e que eram trabalhados com os alunos com a nossa participação no cotidiano da sala de aula, visando identificar as estratégias cognitivas usadas pelos alunos na produção da escrita; potencializar as competências e habilidades textuais e desenvolver as capacidades autorais. Ao longo do processo, o professor de Artes incorporou-se às atividades pedagógicas e foram feitos, pelos alunos, sob sua orientação, vídeos com roteiros, cartazes, fotografias e teatro com o objetivo de desenvolver a livre expressão e a consciência crítica da turma, em que a temática central foi a "realidade dos alunos", com recortes e adaptações dos conteúdos propostos pela matriz curricular para as classes de aceleração.

Nessa perspectiva, podemos inferir que o currículo foi adquirindo forma e significado ao longo do período letivo, decorrente das práticas docentes que foram desenvolvidas no cotidiano da escola, sendo, portanto, tais práticas entendidas de acordo com Lopes e Macedo (2011, p. 19), como um conjunto de "[...] experiências/situações de aprendizagem de forma a levar a cabo um processo educativo", tornando-se, assim, o currículo um elemento que dá materialidade a uma realidade curricular.

A proposta curricular "oficial", que é imposta às escolas da rede pública pela equipe gestora da educação local, traz um currículo com "prescrições". Contudo, apesar de formatado e engessado, as práticas docentes, no espaço escolar, adquiriram contornos próprios em razão do protagonismo dos professores. Num trecho selecionado da entrevista com a professora de Língua Portuguesa, ela apresenta seu modo de entender as formas de trabalhar e a proposta curricular "oficial". Sua fala ilustra este fato. Vejamos: 
DOI: $10.12957 / \mathrm{e}-\mathrm{mosaicos} .2020 .51201$

Pesquisadora: Vocês recebem alguma matriz curricular da SEMED?

Professora: A gente recebe sim, a matriz curricular com o geral. Todo ano a gente reúne. E daí você vai ver o que vai trabalhar. Aí o professor modela o que vai trabalhar com os grupos [aceleração]. [...]

Pesquisadora: Você visou muito o vocabulário [...] qual o seu objetivo ao utilizar este material [o dicionário]?

Professora: [...] Todo tempo que a gente se reúne para formar o que vai trabalhar com os grupos [aceleração], o objetivo principal é fazer o aluno escrever, ler, entender, interpretar o que estão lendo [...]. (Entrevista com a Professora Y, Português, da escola azul, grifos nossos).

A evidência de uma recontextualização fica clara quando a professora revela que "modela o que vai trabalhar" (sic) ou que os professores conversam e decidem o que vão ensinar: "a gente se reúne para formar o que vai trabalhar com os grupos" (sic) ou seja, o professor dará contornos próprios àquilo que foi prescrito ou como nos mostram Matos e Paiva (2007, p. 192) quando afirmam que

\footnotetext{
"[...] a mescla das novas propostas com as pré-existentes, configurase no interior desse espaço de recontextualização. Daí a importância do entendimento do mencionado processo como indicativo de novas oportunidades para o currículo, considerados os diferentes resultados a que pode conduzir" (MATOS; PAIVA, 2007, p. 192).
}

Ademais, a política curricular, entendida como um texto que circula e que sofre a ação de múltiplos contextos, passa por transformações, negociações e adaptações que são decorrentes das práticas pedagógicas que são realizadas na sala de aula no cotidiano da escola. Nesse sentido, retomando Ball $(2000)$ e Lopes $(2005,2008)$, que nos revelam a potência que o conceito de recontextualização por hibridismo traz, permite-nos compreender que uma orientação "oficial", ao circular na rede municipal, passa por (re)interpretações, sendo modificada e ressignificada pelas mediações dos sujeitos educativos e suas práticas pedagógicas na condução do trabalho escolar no cotidiano da instituição de ensino.

\section{A PRODUÇÃO DA ESCRITA E A CONSTRUÇÃO DA COMPETÊNCIA TEXTUAL}

A escrita é denominada por alguns, no senso comum, como um dom sublime de pessoas excepcionais, porém, de acordo com Koch; Elias (2014), a produção da escrita é considerada fruto de um processo que lida com diferentes estratégias que vão além do "redigir" como ler, analisar, expressar-se na oralidade, cooperar, dialogar e respeitar. Podemos considerar o aluno do ensino fundamental como um escritor iniciante, o qual está sempre diante de textos finalizados e que, com isso, acaba apenas focalizando o produto pronto e não todas as etapas contidas no processo de escrita. Uma possível explicação para isso acontecer é o fato de que, atualmente, vivemos em uma sociedade imediatista. Geraldi (2012) relata que o ensino da 
produção da escrita se encontra em um campo paradoxal, visto que para redigir um texto precisamos refletir, (re)editar, enraizar e, obviamente, de tempo. Mas como dar a devida atenção a este ensino se, hoje em dia, "tempo é dinheiro?". No entanto, em meio às tecnologias, os alunos se veem diante de muitas funcionalidades e muitos processos, sendo esses velozes - seja em suas redes sociais, em seus jogos eletrônicos, etc. Porém, quando o mesmo ocorre em sala de aula, se deparam com um trabalho que impõe processos e que demandam tempo. Dessa forma, muitas vezes, os alunos não sentem prazer em ser produtores, diferentemente do que ocorre quando são somente consumidores - isso porque o consumo é fugaz, então consomem a escrita. Atitude diferente ocorre diante da produção escrita, ao menos da que é exigida pela escola, que encerra um processo demorado, com idas e voltas ao mesmo material. Em contrapartida, Passarelli (2012, p. 146) aborda que Krashen (1984) atestou que há uma relação significativa entre a leitura voluntária e a habilidade da escrita (pensemos nela, como algo que dá prazer de ler, de consumir), e que tal ato contribui para a produção do aluno. Então, se os alunos lidam com textos, em sala de aula, cujo tema é do interesse deles ou que foram selecionados por eles, consequentemente se sentem estimulados, conseguem se expressar, o que os faz produzir mais e elevar a escrita.

Dialogando com as ideias do professor João Wanderley Geraldi, em entrevista para o canal digital denominado Linguagem na Lata $^{4}$, ressaltamos que ele chama a atenção para o ensino da escrita nas instituições escolares. 0 referido professor expressa que os gêneros da própria esfera social dos alunos não se fazem presentes no ambiente escolar, o que pode dificultar a produção da escrita. Assim sendo, é notável que tal produção se torne maquinaria e mecânica, sendo visados somente o produto final e a rapidez com que é feito; ou seja, deixando de lado suas etapas e a reflexão sobre o texto construído, pois ambas deixam de existir, o que pode ser ilustrado pela frase expressa pelo professor, quando ele diz: "A juventude contemporânea está obesa de informação e anoréxica de reflexão" (GERALDI, 2020).

Todavia, com o intuito de adequar o ensino em sala de aula, a Base Nacional Comum Curricular - BNCC, homologada em 2017, aborda uma proposta de educação integral, ou seja, desenvolver as dimensões cognitivas, acadêmicas, intelectuais, culturais, sociais, etc., além de desenvolver competências gerais, dentre elas o senso crítico e a compreensão dos alunos.

Para o ensino da Língua Portuguesa, em específico, como a língua se transforma ao longo do tempo, a BNCC contempla esta transformação - dessa forma, há reflexão sobre 0 uso da língua. Além de trabalhar a oralidade, que é o novo eixo incluído, a BNCC apresenta e reconhece a variedade linguística que está presente no convívio social dos alunos. Cabe dizer que, ao expor tais variedades, não se elimina o ensino da norma culta, mas aponta-se para a adequação contextual. É possível verificar, de

4 Canal de Youtube do Departamento de Letras da Universidade Federal do Rio Grande do Norte, criado em 2019, o qual possui o intuito de partilhar conhecimento e assuntos científicos acerca da área da Linguagem. Disponível em: https://www.youtube.com/watch?v=LPfpFa3yyjQ\&feature=youtu.be Acesso em:17 mar. 2020. 
DOI: $10.12957 / \mathrm{e}-\mathrm{mosaicos} .2020 .51201$

maneira mais clara, o objetivo da BNCC - da área de Linguagens que engloba a Língua Portuguesa - no fragmento a seguir:

As relações pessoais e institucionais e a participação na vida em sociedade se dão pelas práticas de linguagem. É por meio dessas práticas que os sujeitos (inter)agem no mundo e constroem significados coletivos. As práticas de linguagem permitem a construção de referências e entendimentos comuns para a vida em sociedade e abrem possibilidades de expandir o mundo em que se vive, ampliando os modos de atuação e de relacionar-se (BRASIL, 2016, p. 86).

Portanto, é possível entender que ao trabalhar com diferentes formas textuais, sendo elas as que mais se aproximam da sua oralidade e de seu contexto social, os alunos utilizarão os próprios recursos expressivos. Foi possível presenciar tal teoria na prática durante o trabalho de campo, no qual em parceria com a professora de Língua Portuguesa, realizamos uma oficina com os alunos, da turma que acompanhamos, cujo objetivo era fazê-los construírem um texto em que dissertassem sobre seu futuro. Dessa maneira, foi possível notar que os alunos se viam mais tranquilos e interessados ao desenvolverem um texto em que dissertavam sobre a vida deles. Em entrevista, destacamos a fala da aluna Y, da GIII que é ilustrativa deste fato:

Pesquisadora: Quando a gente chega e fala assim "título: como me vejo no futuro?", é mais fácil de você fazer?

Aluna Y: É...

Pesquisadora: Por quê?

Aluna Y: Porque a gente vai falar o que a gente, tipo assim, o que a gente quer que seja pra gente [...]. Ah bom, podia me ver o futuro assim: trabalhando, tendo a minha casa, tipo assim, é bem mais fácil do que a gente falar, ler um texto e escrever sobre o texto. (grifo nosso)

Observamos, então, o quanto era estimulante para a aluna dissertar sobre aquilo de que tinha conhecimento, conectividade e vivência. $O$ que nos mostra esta evidência é que a produção da escrita se torna mais fluida e mais produtiva quando a proposta parte do "mundo"; da experiência dos alunos. Portanto, entende-se que o papel da escola é ser uma instituição, na qual a liberdade - de poder trabalhar com diferentes formas textuais - para a produção da escrita e também para a leitura deve se fazer presente no cotidiano e, com isso, tornar possível o desenvolvimento do potencial de escrita dos alunos. 
DOI: $10.12957 / \mathrm{e}-\mathrm{mosaicos} .2020 .51201$

\section{NORMA CULTA X NORMA-PADRÃO5: INFLUÊNCIAS PARA A PRODUÇÃO DA ESCRITA}

Entendemos que há um avanço, no âmbito escolar, para o ensino de produção textual, visto que os textos que são apresentados aos alunos deixam de ser antinaturais - o que pode se aproximar da realidade da comunicação. Isso nos revela, de acordo com Faraco (2008), que as instituições de ensino reconheceram a variedade linguística, porém esta abordagem didática ocorre a passos lentos. É importante dizer que a proposta da BNCC é a de que os alunos possam trabalhar com as diferenças linguísticas, com a sua oralidade, adequando-as em contextos específicos, os quais derrubam o mito, como nos adverte Valverde (2019), de que a língua é homogênea, principalmente ao utilizar sua própria linguagem, colocando em questionamento os paradigmas, que são próprios da sua comunidade de fala: "[...] colocando atenção sobre similaridades, regularidades e diferenças de formas e de usos linguísticos, levantando hipóteses sobre as condições contextuais e estruturais em que se dão. [...]" (BRASIL, 1998, p. 28). Assim, ao longo do seu processo de escolarização, os alunos terão oportunidades de operar sobre a própria linguagem, sobre os textos que produzem, organizando e registrando suas intuições num processo que envolve diversas operações mentais. Contudo, apesar dos avanços em relação ao ensino de gramática, a associação sujeito-escrita segue sendo um dos maiores fatores que corroboram para a defasagem de uma produção textual bem sucedida, que é onde lançamos nosso olhar no estudo que realizamos. Tal afirmação pode ser observada na fala da professora da turma GIII. Vejamos:

Pesquisadora: O PCN de 98, ele vai falar que dentro de sala de aula a gente tem que abordar a norma culta [...]. Você consegue abordar essa norma culta dentro de sala de aula?

Professora: Você não consegue porque a língua falada ela é uma língua mais coloquial e a língua coloquial é a língua que atinge mais os alunos. Pesquisadora: Você sente ou vê se eles possuem alguma dificuldade quando você trabalha essas coisas?

Professora: Muita coisa, em relação à estrutura, eles têm muita dificuldade, tanto que você pega um e você viu ali na prova, que escreve... começa a escrever qualquer coisa com letra minúscula, coisinhas básicas né? Coisas básicas... Pontuação, são difíceis de pontuação, vocabulário é muito restrito. (grifo nosso)

Foi possível observar, no relato acima, que a instituição escolar apresenta dificuldades no momento do ensino da norma culta, visto que os alunos não estão em constante contato com essa norma - devido a fatores geográficos, socioeconômicos, etc. Por esse motivo, por se tratar de algo inédito para alguns, é necessário ter um olhar mais sensível tanto para o ensino quanto para os alunos, seja em como conduzir a aula, como chamar a atenção para o assunto, seja nas estratégias que serão

5 De acordo com Bagno (2017), a norma-padrão pode ser definida como um padronizador de língua, o qual dita regras gramaticais. Já a norma culta, segundo Guerra (2008), é uma variação linguística, a qual aceita tais variações e, consequentemente, não as incrimina. 
utilizadas, a fim de diminuirmos a barreira da língua que é notável para muitos. Compreende-se, portanto, que a norma culta não deve ser imposta, no intuito de condenar as variações linguísticas, mas sim que seja possível o diálogo entre esses dois recursos linguísticos, para que possam ser utilizados em contextos adequados.

Colello (2003) afirma que a instituição escolar trabalha somente com um modelo hegemônico de língua, ou seja, a norma culta, que segue o "Modelo Autônomo de Letramento" que, de acordo com Street (1984 apud COLELLO, 2003, p. 2), irá deixar de lado a pluralidade cultural da linguagem. Mariani (2016, p. 50), por sua vez, propõe uma reflexão ao afirmar que: "usualmente ensinam-se regras de uma forma escrita da língua padrão, que é a da chamada norma culta. Sem dúvida, cabe à escola ensinar a norma, mas não caberia à escola, também, reconhecer a diversidade?" Há uma questão a ser debatida, antes de continuarmos, pois, tanto na fala de Mariani (2016) quanto na de Colello (2003), o conceito de norma culta é "defendido" como um padronizador de língua de caráter abstrato, o qual visa a tradição gramatical. Para Bagno (2003, p. 42) é compreensível haver este equívoco, pois "a maior dificuldade em lidar com a norma culta é precisamente o fato dela ter dupla personalidade.[...]". Ou seja, norma culta compreendida como a norma-padrão e a norma culta que reconhece as variedades linguísticas.

Entende-se, portanto, que a língua varia no tempo e no espaço, consequentemente, ocorre a mudança da língua com o passar dos anos e, por este motivo, seria pertinente que a instituição escolar, em seu papel de precursora do conhecimento acadêmico, lançasse mão de gramáticas descritivas e reflexivas que elevam os estudos linguísticos ao patamar da ciência (Perini, 2010; Castilho, 2010; Bagno, 2011), a fim de fazer com que o aluno sinta-se integrante do ambiente escolar, e, com isso, tenha o seu nível de competência comunicativa elevado.

O que está sendo discutido até então não é a exclusão da norma culta para o ensino de gramática, mas o reconhecimento de uma ciência da linguagem que comprova o caráter heterogêneo da língua.

\section{A CONTRIBUIÇÃO DA LINGUÍSTICA PARA A PRODUÇÃO DA ESCRITA}

Como já citado anteriormente, transportamos algumas características do sistema linguístico - lexicais, gramaticais, etc. - da oralidade para a escrita. Contudo, de acordo com Kato (1986) essa transposição também ocorre de maneira contrária esta questão pode ser compreendida como os quatro estágios do letramento ${ }^{6}$ de um indivíduo. Kenedy (2016, p. 201) explicita que o primeiro estágio é entendido como o pré-letramento, no qual "[...] a cognição linguística do falante do português do Brasil equivale ao que chamamos de vernáculo brasileiro[...]", o que pode ser considerado variável de acordo com o ambiente sociocultural em que o indivíduo está inserido. Já o último estágio pode ser compreendido como a fala letrada, no qual o falante

6 A definição de Letramento, neste caso, refere-se ao que Soares (2002) aborda, ou seja; não somente um processo de saber ler e escrever, mas sim incorporar a escrita em suas práticas sociais. 
brasileiro está em contato com a norma culta e transfere as características desta norma para a oralidade. Entre esses dois estágios, encontram-se duas etapas intermediárias que atentam à evolução da competência linguística do falante letrado/culto e apontam para os processos que levam ao letramento pleno.

Kato (1986) esclarece em seu livro intitulado No mundo da escrita: uma perspectiva psicolinguística, o esquema: fala1 - escrita 1 - escrita2 - fala2, que são considerados os estágios do letramento. Para tal, iremos à explicação: A fala1 representa o estágio do pré-letramento, no qual o indivíduo ainda não possui contato com o universo da escrita. Já a escrita 1 corresponde a fala de uma forma mais naturalizada, ou seja, é a transcrição da oralidade e pode ser entendida como as etapas iniciais da alfabetização. Por sua vez, a escritaz é caracterizada por ser independente da fala, enquanto a falaz é resultante da expansão da escrita, nos levando ao letramento pleno. Vale ressaltar que todo este processo é influenciado pelo ambiente sociocultural em que o indivíduo está exposto, por exemplo: se o sujeito não convive com a oralidade formal em seu dia a dia, o mesmo terá dificuldades ao se deparar com a norma culta na escola. Porém, para quem estiver diariamente em contato com essa norma será muito mais simples, visto que já possui as características lexicais, gramaticais e discursivas resultantes da escrita2 (KENEDY, 2016). Todo este processo é encaminhado por meio da natureza do estímulo auditivo e visual, sendo o primeiro para a fala e o segundo para a escrita. De acordo com Kato (1986, p.20), alguns estudos linguísticos da escrita revelaram que, por mais que ela tenha sido desenvolvida para representar a oralidade, a mesma (a escrita) não é de caráter cem por cento fonético e sim, substancialmente, fonêmico visto que "[...] neutraliza diferenças fonéticas que existem na fala, mas que não são distintas, significativas."

Tais questões desenvolvidas acima, acerca da linguagem e da escrita, podem ser cruciais para entendermos o espaçamento presente entre a oralidade e a escrita o qual pode contribuir para a dificuldade enfrentada pelos alunos ao produzirem um texto. Por estarmos abordando a produção escrita, pensemos nela e em seus diferentes gêneros discursivos. Para tal, podemos atentar para o que nos ensina Kato (1986, p. 20), quando afirma que "[...] as diferenças formais normalmente observadas entre fala e escrita nada mais são do que diferenças acarretadas pelas condições de produção e do uso da linguagem." Essas diferenças, segundo a autora, podem ser entendidas como:

- Dependência contextual: estipula se o texto será de caráter autônomo, levando em conta o contexto.

Grau de planejamento: define o grau de formalidade que será utilizado no texto, podendo ir do mais simples (casual, informal) para o mais complexo (formal, culto, gramatical).

Submissão consciente às regras prescritivas convencionalizadas para a escrita: tal submissão vai depender do grau de formalidade do texto. 
DOI: $10.12957 / \mathrm{e}-\mathrm{mosaicos} .2020 .51201$

Entendemos, portanto, que o ato de escrever, proporciona, de certa forma, a oportunidade para um planejamento verbal mais minucioso. A escrita é mais propensa a se moldar normativamente e, por ser um produto, armazena o conhecimento de maneira ordenada.

É importante citar que as décadas de 1980 e 1990 foram importantes para o avanço das pesquisas na área da Linguística e da subárea Psicolinguística, ainda mais no que diz respeito à produção escrita (WERNER; RODRIGUES, 2018). Nesta mesma época, o ato de escrever foi definido como a tradução da oralidade para a escrita, entretanto, é possível percebermos que a escrita não é uma substituição da fala, mas sim que ela é complementar a mesma. Enquanto para o desenvolvimento da leitura, era necessário seguir as etapas percorrendo as letras, palavras e o texto completo, a escrita era iniciada pelas sentenças.

Para o clássico, o ato de escrever bem é significado de se expressar com maestria (KATO, 1986). Ao efetuar tal modalidade, o escritor consegue se conectar com o leitor ao passo que esse consegue compreender as intenções implícitas no texto. Enquanto para o ato da leitura, o foco é apenas em um método, para a escrita os estudos viabilizam os modelos processuais, que, em conjunto, contribuem para tal. Como nos ensina Rodrigues (2012, p. 12), "A escrita é uma atividade com uma dimensão social, cognitiva e linguística, pois surge num contexto social, seguindo determinados objetivos e normas, sendo vista, cognitivamente, como uma atividade complexa [...]". De acordo com Werner e Rodrigues (2018), tanto o grau de experiência do leitor quanto seu entendimento sobre o assunto que irá redigir, influenciarão tal produção. Além disso, tanto o ato de revisar o texto quanto o acionamento da memória de longo prazo contribuirão para o desenvolvimento das etapas da produção da escrita.

Sabemos, então, que a escrita é um produto e que a mesma envolve processos e subprocessos em sua construção e, para compreendê-los, iremos analisar tópicos teóricos como Hayes \& Flower (1980). Além de mapeá-los, explicaremos como esses são organizados na geração da produção da escrita. Para os processos temos: o contexto da produção da tarefa, a memória de longo prazo e o processo da escrita.

O contexto da produção da tarefa é definido como tudo o que está no ambiente externo à mente do escritor e pode, de certa forma, influenciá-lo e/ou motivá-lo no momento da produção; seja tanto na definição do público-alvo, quanto na temática a ser desenvolvida, tal qual explicam Werner e Rodrigues (2018). Para obter uma composição fácil de ser construída, aciona-se a memória de longo prazo, a qual pode ser estabelecida como um armazenamento interno sobre determinado assunto, público-alvo e até mesmo o planejamento textual. Estes elementos trazidos pelos autores, podem ser observados nas entrevistas realizadas com os alunos $\mathrm{X}$ e $\mathrm{W}$ :

Pesquisadora: Pode me explicar como você produz um texto? Tipo... como você processa a escrita de um texto para depois colocar no papel? 
DOI: $10.12957 /$ e-mosaicos.2020.51201

Aluno X: Todo texto que eu faço, eu penso em mim [...]tudo que eu já passei, tudo que aconteceu [...] Quando não tem, aí eu vejo o que aconteceu com uma outra pessoa próxima de mim, aí eu escrevo.

Aluna W: [...] Pra falar de mim, eu faço mais rápido. (grifo nosso)

Dessa forma, verifica-se que os alunos acessam a memória de longo prazo e isso permite que compreendamos que o escritor possui certo conhecimento sobre 0 que está redigindo e enfatiza que, ao escrever sobre o que já se conhece como, por exemplo, sua vida pessoal, a tarefa é facilitada, como explicita o aluno $\mathrm{X}$ dizendo: "Todo texto que eu faço, eu penso em mim [...] tudo que eu já passei, tudo que aconteceu [...]. Esta evidência revela que a produção se torna mais fácil de ser conduzida por ele. Por fim, há o processo da escrita, o qual é definido como o texto propriamente dito - tal processo é dividido em três subprocessos que são:

- Planejamento: organiza-se as ideias para o texto (como começar, quais palavras usar, objetivos etc.) e é, também, onde fazemos uso da memória de longo prazo, a fim de estimular as idealizações que são necessárias para a formação da unidade textual.

- Tradução: transportam-se as ideias realizadas no planejamento em formato de sentenças, ou seja, traduzimos essas ideias para o texto em si. É nesta etapa que a produção começa a tomar forma.

Revisão (releitura e edição): etapa avaliativa, na qual o escritor se coloca na posição de leitor e inspeciona a obra fazendo alterações, adicionando ou suprimindo informações. É responsável, também, por clarear o texto seja em sua linguagem, estrutura e/ou conteúdo.

A partir da perspectiva de Werner e Rodrigues (2018), podemos observar os três subprocessos preconizados por elas, no trecho da entrevista da aluna $\mathrm{Y}$, conforme ilustramos abaixo:

Pesquisadora: Quais são as etapas que você constrói até chegar nesse resultado final?

Aluna Y: Então, fico criando o texto primeiro, ai fico botando um bando de coisa: ah, essa parte está boa? Essa parte não está boa? Aí tipo assim, é aí que eu consigo fazer o texto, porque eu vou escrevendo e vou criando o texto, vou escrevendo e vou tirando da mente.

Pesquisadora: Quando você escreve tudo, você olha de novo ou você escreveu e está bom?

Aluna Y: Não. Eu escrevi e fico lendo pra ver como ficou e depois eu entrego pra professora.

Pesquisadora: E demora você fazer o texto?

Aluna Y: [...] pra falar de texto eu demoro um pouco, que eu fico lendo e relendo, lendo e relendo, lendo e relendo, pra poder botar um negócio maneiro. (grifo nosso) 
Como verificamos acima, os processos são perceptíveis na prática e, por este motivo, iremos explicá-los, já que temos a evidência. No primeiro trecho, a aluna $Y$ parte do planejamento, no qual no processo cognitivo, de fato, planeja o que irá escrever. Isto fica evidenciado na fala: "[...] fico criando o texto primeiro, fico botando um bando de coisa: ah, essa parte está boa? Essa parte não está boa?". É importante dizer que, com frequência, os alunos no momento da produção da escrita não costumam se utilizar deste processo, já que pensar e planejar o texto demanda tempo. Passarelli (2012) salienta que por não planejar anteriormente, os alunos esperam que o texto - que não seja de seu conhecimento - simplesmente "caia do céu", o que se torna contraditório, pois pensar anteriormente economiza tempo no momento da produção. Na mesma fala "[...] ah, essa parte está boa? Essa parte não está boa? [...]", também é possível perceber a utilização, ou tentativa, da memória de longo prazo na qual a aluna verifica se as informações serão aproveitadas ou não. Em termos gerais, esse processo de sondagem é efetuado três vezes, em média, visto que quando se acessa tal memória e percebe-se que já encontrou o que precisava para a construção do texto, não é necessário voltar (PASSARELLI, 2012).

No trecho seguinte "[...] vou escrevendo e vou tirando da mente. $[\ldots]$ ", ocorre a tradução, ou seja, na qual sai de um plano mental e transporta para o concreto , em que suas ideias e pensamentos tomam forma na escrita - é importante esclarecer que não se trata do texto pronto, visto que está somente no início e há mais processos para percorrer até o produto final. É neste momento da tradução que direcionamos o caminho para a construção da produção; tanto no parágrafo quanto nas conjunções, o que faz com que o texto adquira forma. Como nos indica Passarelli (2012, p 159), "[...] alguns estudantes acabam por escolher seu estilo, de acordo com o que mais se adapta a seu modo de pensar e à sua realidade".

Ambos os processos, já citados, encaminham para a revisão, a qual, como o nome já diz, é realizada para ver o texto novamente - atentando-se à coerência, coesão, ortografia, etc. Quando a aluna relata "[...] que eu fico lendo e relendo, lendo e relendo, lendo e relendo, pra poder botar um negócio maneiro.", ela (re)formula as ideias vindas do planejamento, que foram transcritas na tradução e as revisa, construindo um texto completo. É neste momento também que a própria escritora, neste caso a aluna, torna-se leitora, pois ela precisa saber se a produção está coerente. Dessa forma, com a revisão, a reescrita também ocorre, para adequar o texto tornando-o compreensível. Por fim, a fala "[...] Eu escrevi e fico lendo pra ver como ficou e depois eu entrego pra professora." pode ser compreendida como a finalização do texto, ou seja, a aluna percorreu todas as etapas e, no fim, a produção textual foi realizada com sucesso, de acordo com a visão da aluna.

Vale ressaltar que esses processos não ocorrem de forma linear - já que alguns caminhos cognitivos podem se cruzar, contribuindo para a alteração do texto em qualquer momento (HAYES \& FLOWER, 1980), além de possuírem funções definidas, ou seja, cada etapa exerce uma finalidade específica. Esse modelo possui uma espécie de "Monitor", no qual articula o planejamento com a revisão, ou seja, enquanto 
DOI: $10.12957 /$ e-mosaicos.2020.51201

organizamos as ideias e montamos as frases no papel, o monitoramento é feito a fim de verificarmos nossa atuação para com o texto (WERNER; RODRIGUES, 2018).

\section{CONSIDERAÇõES AINDA PARCIAIS...}

No trabalho de campo que realizamos, constatamos a complexidade do currículo, das práticas pedagógicas que giram em torno dele e a infinita possibilidade de recriação das políticas curriculares locais, para além das previsões de seus idealizadores que não consideram a dinâmica institucional, a cultura escolar e os grupos sociais que habitam o espaço escolar, que se constituem em universos muito singulares. Verificamos, também, que a produção da escrita vai além de um conjunto de palavras, temas, estruturas e que fatores culturais e sociais podem impactar em tal produção. Ela envolve não só o texto propriamente dito, mas também diversos processos que nos conduzem até chegarmos ao produto final.

A Linguística, como ciência básica, contribui para o nosso entendimento de como são os processos cognitivos envolvidos na produção da escrita, a fim de não somente verificarmos aspectos da superficialidade textual como, por exemplo, erros ortográficos, concordância, regência, mas também de efetuarmos uma verificação do conteúdo ensinado juntamente com os objetivos e com os conhecimentos prévios. Pode ser compreendido que os alunos direcionam sua atenção, muitas vezes, para as questões gramaticais, deixando de lado a coerência da produção e, de fato, isso acontece, pois estão visando a nota. Contudo, foi possível analisar mais a fundo todo o contexto, desde a entrada do aluno no ambiente escolar, a sua vivência e como ele produz os processos e subprocessos na prática da escrita em sala de aula.

Em suma, esperamos que este artigo possa ser referência para aqueles que buscam compreender a construção do currículo no cotidiano escolar, o desenvolvimento das práticas pedagógicas e como ambos podem impactar a produção da escrita e todos os processos que a cercam, tanto de maneira externa quanto de maneira interna.

\section{REFERÊNCIAS}

BAGNO, Marcos. A norma oculta: língua e poder na sociedade brasileira. São Paulo: Parábola Editorial, 2003. v. 1, p. 39-63. 223-225.

. Dicionário crítico de sociolinguística. 1. ed. São Paulo: Parábola, 2017. v. 1, p. Gramática pedagógica do português brasileiro. 1. ed. São Paulo: Parábola Editorial, 2011. 
DOI: $10.12957 / \mathrm{e}-\mathrm{mosaicos} .2020 .51201$

BALL, Stephen J. Cidadania Global, consumo e política educacional. In: SILVA, Luiz Heron da (org). A escola cidadã no contexto da globalização. 4. ed. Petrópolis: Vozes, 2000. p.121-137.

BRASIL. Ministério da Educação. Base Nacional Comum Curricular. 2. ed. Brasília: MEC/SEB, 2016. p. 86-88. Disponível em:

$<$ http://www.consed.org.br/download/base-nacional-comum-curricular-2a-versaorevista> Acesso em: 29 abr. 2020.

BRASIL. Parâmetros Curriculares Nacionais (PCNs). Língua Portuguesa. Ensino Fundamental. Terceiro e quarto ciclos. Brasília: MEC/SEF, 1998. p. 28-29.

CASTILHO, A. T. . Nova Gramática do Português Brasileiro. 1. ed., $1^{\circ}$ Reimpressão. São Paulo: Editora Contexto, 2010.

COLELLO, Silvia M. Gasparian. A Pedagogia da Exclusão no Ensino da Língua Escrita. Videtur, n. 23, Porto: Mandruvá, 2003. Disponível em:

<http://www.hottopos.com/videtur23/silvia.htm> Acesso em: 17 dez. 2019.

CORSARO, William A. Entrada no Campo, Aceitação e Natureza da Participação nos Estudos Etnográficos com Crianças Pequenas. Educ. Soc., Campinas, vol. 26, n. 91, Maio/Ago. 2005. p. 443-464. Disponível em:

<http://www.scielo.br/pdf/es/v26n91/a08v2691> Acesso em: 13 dez. 2019.

FARACO, C. A. Norma culta brasileira: desatando alguns nós. 1. ed. São Paulo: Parábola Editorial, 2008. p. 73-85; 165-178.

FLOWER, Linda; HAYES, John R. Identifying the organization of writing processes. In: L.W. Gregg, E.R. Steinberg (Ed). A cognitive process theory of writing. 1. ed. Hillsdale, New Jersey: Erlbaum, 1980. p. 3-30. Disponível em:

<https://www.researchgate.net/publication/200772468_Identifying_the_organization_of _writing_processes> Acesso em: 12 mai. 2020.

GERALDI, João Wanderley. Entrevista proferida no Linguagem na lata, jan. 2020. Disponível em: <https://www.youtube.com/watch?v=LPfpFa3yyjQ\&feature=youtu.be> Acesso em: 17 mar. 2020.

GERALDI, João Wanderley. Enraizamento em tempos acelerados. Prefácio. In: PASSARELLI, L. G. Ensino e correção na produção de textos escolares. 1. ed. São Paulo: Cortez, 2012. p.15-19.

GOODSON, Ivor F. A construção social do currículo. Lisboa: EDUCA, 1997.

GUERRA, Pollianny N. M. Norma culta e norma-padrão: desfazendo os sinônimos. Parlatorium, v. 01, p. 1-9, 2008. Disponível em: <http://www.faminasbh.edu.br/upload/downloads/201112061824034532.pdf> Acesso em: 13 abr. 2020. 
DOI: $10.12957 / \mathrm{e}-\mathrm{mosaicos} .2020 .51201$

KATO, Mary A. No mundo da escrita: uma perspectiva psicolinguística. São Paulo: Ática, 1986, p. 7-41.

KENEDY, E . O status da norma culta na Língua-I dos brasileiros e seu respectivo tratamento na escola: algumas contribuições de estudos formalistas à educação. In: Simone Guesser. (Org.). Linguística: pesquisa e ensino. 1. ed. Boa Vista: EDUFRR, 2016, v. 1, p. 173-196.

$\mathrm{KOCH}$, Ingedore Villaça; ELIAS, Vanda Maria. Ler e Escrever: estratégias de produção textual. 2. ed., $2^{a}$ reimpressão - São Paulo: Contexto, 2014.

LOPES, Alice C. Política de Currículo: recontextualização e hibridismo. Currículo sem Fronteiras, v.5, n.2, p.50-64, jul/dez, 2005. Disponível em:

<http://www.curriculosemfronteiras.org/vol5iss2articles/lopes.pdf> Acesso em: 10 dez. 2019.

A recontextualização por hibridismo. In: LOPES, Alice C. Políticas de Integração Curricular. Rio de Janeiro: EDUERJ, 2008. p.27-32.

LOPES, Alice C; MACEDO, Elizabeth. Teorias de Currículo. São Paulo: Cortez, 2011.

MARIANI, Bethania. O Político, o Institucional e o Pedagógico: quanto vale a língua que ensinamos? Matraga, Rio de Janeiro, RJ, v.23, n.38, jan/jun, p. 43- 60. 2016. Disponível em: https://www.e-publicacoes.uerj.br/index.php/matraga/article/view/21202 Acesso em: 17 dez. 2019.

MATOS, Maria do Carmo; PAIVA, Edil V. de. Hibridismo e Currículo: ambivalências e possibilidades. Currículo sem Fronteiras, v.7, n.2, p.185-201, jul/dez, 2007. Disponível em: <http://www.curriculosemfronteiras.org/vol7iss2articles/matospaiva.pdf> Acesso em: 27 jan. 2020.

PASSARELLI, L. G. Ensino e correção na produção de textos escolares. 1. ed. São Paulo: Cortez, 2012. p. 143-175.

PERINI, M. A. Gramática do português brasileiro. 1. ed. São Paulo: Parábola Editorial, 2010.

RODRIGUES, Marta Maria R. Os subprocessos do processo de escrita. 2012. $443 \mathrm{f}$. Projeto de Intervenção (Mestrado em Didática da Língua Portuguesa) - Instituto Politécnico de Lisboa, Escola Superior de Educação. 2012. p. 1-17.

SACRISTÁN, José G. O Currículo: uma reflexão sobre a prática. Tradução Ernani F. da F. Rosa. 3. ed. Porto Alegre: ArtMed, 2000. p. 13-95; 165-223.

SILVA, T. T. da. Documentos de identidade: uma introdução às teorias do currículo. 2. ed. Belo Horizonte: Autêntica. 2002. 
DOI: $10.12957 / \mathrm{e}-\mathrm{mosaicos} .2020 .51201$

SOARES, Magda. Novas práticas de leitura e escrita: letramento na cibercultura. Educ. Soc. [online]. 2002, vol.23, n.81, p. 144-146. Disponível em: <http://dx.doi.org/10.1590/S0101-73302002008100008> Acesso em: 15 mai. 2020.

TARDIF, M. O trabalho docente: elementos para uma teoria da docência como profissão de interações humanas. 4. ed. Petrópolis, RJ: Vozes, 2008.

TURA, Maria de Lourdes R. Conhecimento escolares e a circularidade entre culturas. In: LOPES, Alice C; MACEDO, Elizabeth (org). Currículo: debates contemporâneos. São Paulo: Cortez, 2002, p.150-173. (Série cultura, memória e currículo, v.2).

VALVERDE JÚNIOR, Walter Pereira. O ensino da língua escrita culta: as múltiplas gramáticas como chave para novas práticas docentes. 2019. 120f. Dissertação (Mestrado Profissional em Letras) - Universidade do Estado do Rio de Janeiro, Faculdade de Formação de Professores. 2019. p. 13-35.

WERNER, E. F. de A.; RODRIGUES, Érica dos S. O processo de revisão na produção escrita e questões de correferência. 2018. 246f. Tese (Doutorado em Psicolinguística) Pontifícia Universidade Católica do Rio de Janeiro, Departamento de Letras. 2018. p. 32-36.

Recebido em 22 de maio de 2020

Aceito em 18 de julho de 2020

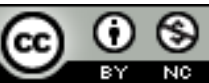

A e-Mosaicos Revista Multidisciplinar de Ensino, Pesquisa, Extensão e Cultura do Instituto de Aplicação Fernando Rodrigues da Silveira (CAp-UERJ) está disponibilizada sob uma Licença Creative Commons - Atribuição-NãoComercial 4.0 Internacional.

Os direitos autorais de todos os trabalhos publicados na revista pertencem ao(s) seu(s) autor(es) e coautor(es), com o direito de primeira publicação cedido à e-Mosaicos.

Os artigos publicados são de acesso público, de uso gratuito, com atribuição de autoria obrigatória, para aplicações de finalidade educacional e não-comercial, de acordo com o modelo de licenciamento Creative Commons adotado pela revista. 